\title{
Genomic and proteomic profiling II: Comparative assessment of gene expression profiles in leiomyomas, keloids, and surgically-induced scars
} Xiaoping Luo1, Qun Pan¹, Li Liu² and Nasser Chegini*1

\author{
Address: ${ }^{1}$ Department of Obstetrics and Gynecology, University of Florida, College of Medicine, Gainesville, Florida 32610, USA and \\ 2Interdisciplinary Center for Biotechnology Research, University of Florida, College of Medicine, Gainesville, Florida 32610, USA \\ Email: Xiaoping Luo - xiaoping@obgyn.ufl.edu; Qun Pan - panq@obgyn.ufl.edu; Li Liu - liliu@biotech.ufl.edu; \\ Nasser Chegini* - cheginin@obgyn.ufl.edu \\ * Corresponding author
}

Published: 24 August 2007

Reproductive Biology and Endocrinology 2007, 5:35 doi:10.1 186/1477-7827-5-35

This article is available from: http://www.rbej.com/content/5/1/35

(c) 2007 Luo et al; licensee BioMed Central Ltd.

This is an Open Access article distributed under the terms of the Creative Commons Attribution License (http://creativecommons.org/licenses/by/2.0), which permits unrestricted use, distribution, and reproduction in any medium, provided the original work is properly cited.
Received: 15 May 2007

Accepted: 24 August 2007

\begin{abstract}
Background: Leiomyoma have often been compared to keloids because of their fibrotic characteristic and higher rate of occurrence among African Americans as compared to other ethnic groups. To evaluate such a correlation at molecular level this study comparatively analyzed leiomyomas with keloids, surgical scars and peritoneal adhesions to identify genes that are either commonly and/or individually distinguish these fibrotic disorders despite differences in the nature of their development and growth.
\end{abstract}

Methods: Microarray gene expression profiling and realtime PCR.

Results: The analysis identified 3 to $12 \%$ of the genes on the arrays as differentially expressed among these tissues based on $\mathrm{P}$ ranking at greater than or equal to 0.005 followed by 2 -fold cutoff change selection. Of these genes about 400 genes were identified as differentially expressed in leiomyomas as compared to keloids/incisional scars, and 85 genes as compared to peritoneal adhesions (greater than or equal to 0.01 ). Functional analysis indicated that the majority of these genes serve as regulators of cell growth (cell cycle/apoptosis), tissue turnover, transcription factors and signal transduction. Of these genes the expression of E2FI, RUNX3, EGR3, TBPIP, ECM-2, ESMI, THBSI, GASI, ADAMI7, CST6, FBLN5, and COLI8A was confirmed in these tissues using quantitative realtime PCR based on low-density arrays.

Conclusion: the results indicated that the molecular feature of leiomyomas is comparable but may be under different tissue-specific regulatory control to those of keloids and differ at the levels rather than tissue-specific expression of selected number of genes functionally regulating cell growth and apoptosis, inflammation, angiogenesis and tissue turnover.

\section{Background}

Leiomyomas are benign uterine tumors with unknown etiology that originate from transformation of myometrial smooth muscle cells and/or connective tissue fibrob- lasts during the reproductive years. Leiomyomas can develop in multiple numbers that are individually encapsulated by a connective tissue core separating them from the surrounding normal myometrium and are ovarian 
steroid-dependent for their growth. Although they occur independent of ethnicity, clinical and epidemiological studies have indicated that African Americans are at a higher risk of developing leiomyomas compared to other ethnic groups [1].

Leiomyomas have also often been compared to keloids because of a higher rate of occurrence in African Americans and their fibrotic characteristics despite differences in the nature of their development and growth [2]. Keloids are benign skin lesions that develop spontaneously, or form from proliferation of dermal cells following tissue injury resulting in a collagenous and poorly vascularized structure at later stage of their development [3-6]. Unlike surgically-induced and hypertrophic scars that are confined to the area of original tissue injury, keloids can expand beyond the boundaries of their original sites following removal and during healing. Keloids are rather similar to hypertrophic scars at early stages of development, however they become collagenous and poorly vascularized at later stages and tend to occur more frequently in darker skinned individuals $[3,4]$. Surgically-induced injury and/or inflammation also result in peritoneal scar or adhesions and similar to other incisional scars they are confined to the area of tissue injury[7]. Peritoneal adhesions also display a considerable histological similarity with dermal scars; however there is no data to suggest a higher risk of adhesion formation with ethnicity. Comparatively, uterine tissue injury i.e., following myomectomy or cesarean sections, does not cause leiomyomas formation, but rather results in incisional scar formation at the site of injury. Furthermore, leiomyomas consist mainly of smooth muscle cells forming a relatively vascuraized tissue, while keloids derive from proliferation of connective tissue fibroblasts, adopting a myofibroblastic phenotype at a later stage of wound healing $[3,4]$.

As part of these characteristics previous studies have identified excess production and deposition of extracellular matrix, namely collagens in leiomyomas, keloids, hypertrophic and surgical scars and peritoneal adhesions [2,710]. Evidence also exists implicating altered production of several proinflammatory and profibrotic cytokines, proteases and adhesion molecules in pathogenesis and characteristic of these and other fibrotic disorders [11-14]. Large-scale gene expression studies have provided additional evidence for the expression of a number of differentially expressed genes in leiomyomas [11,15-17], keloids and hypertrophic scars $[15,16]$ as compared to their respective normal tissues. Several conventional studies have demonstrated that the products of some of these genes regulate various cellular activities implicated in the outcome of tissue fibrosis at various sites throughout the body Among these genes, include several growth factors and cytokines such as TGF- $\beta$ system, proteases, adhesion molecules and extracellular matrix etc. (for review see [717]). Despite these advancements, the biological significance of many of these genes in pathophysiology of leiomyomas and keloids and their relationship to the outcome of other tissue fibrosis remains to be established. In addition, there has not been any study that comparatively analyzed the molecular profile that distinguishes leiomyomas from other fibrotic tissues, specifically keloids.

Considering these characteristics we used large-scale gene expression profiling to evaluate such a correlation at molecular level by comparatively analyzing leiomyomas with keloids, surgical scars and peritoneal adhesions to identify genes that are either commonly and/or individually distinguish these fibrotic disorders despite differences in nature of their development and growth. We evaluated the expression of 12 genes in these tissues representing several functional categories important to tissue fibrosis using quantitative realtime PCR based on low-density arrays.

\section{Methods}

All the materials and methods utilized in this study are identical to our previous studies and those reported in the accompanying manuscript $[11,17]$. Prior approval was obtained from the University of Florida Institutional Review Board for the experimental protocol of this study, with patients with scars giving informed consent, while the study with leiomyomas was expedited and did require obtaining written informed consent.

Total cellular RNA was isolated from keloid/incisional scars $(\mathrm{N}=4)$ and subjected to microarray analysis using human U133A Affymetrix GeneChips as described in the accompanying manuscript [17]. One patient who had developed keloid at the site of previous surgical incision also developed leiomyoma. All the patients with keloids and one patient with incisional scar were African Americans. In addition, we utilized the gene expression data obtained from our previous study [11] involving leiomyomas $(\mathrm{N}=3)$ and peritoneal adhesions $(\mathrm{N}=3)$ using human U95A GeneChips. These tissues were from Caucasians patients with the exception of one peritoneal adhesion collected from an African American patient. The age of patients with leiomyomas ranged from 29 to 38 years. These women were not taking any medication, including hormonal therapy, for pervious 3 months prior to surgery and based on their last menstrual period and endometrial histology was from early-mid secretary phase of the menstrual cycle. The age of patients with adhesions ranged from 25 to 46 years and those with keloids and surgical scars were 26, 32 and 39 years, respectively. All the tissues with the exception of one keloid matched by their corresponding normal tissues i.e. myometrium, skin and pari- 
etal peritoneum for microarry analysis. All the procedures for total RNA isolation, amplification, cDNA synthesis, RNA labeling and hybridization into the GeneChips were carried out as previously described in detail [11].

\section{Microarray data analysis}

The gene expression values obtained from the leiomyomas and matched myometrium $(\mathrm{N}=6)$ using U133A GeneChips in the accompanying manuscript was utilized here only for the purpose of comparative analysis. The gene expression values obtained from all U133A and U95A GeneChips were independently subjected to global normalization and transformation, and their coefficient of variation was calculated for each probe set across the chips as previously described [11]. The selected gene expression values were than subjected to supervised learning including statistical analysis in $\mathrm{R}$ programming and ANOVA with Turkey test and gene ranking at $\mathrm{P} \leq 0.005$ followed by 2 -fold change cutoff[11]. Functional annotation and molecular pathway analysis was carried out as described [17].

For combining the data from the U95A and U133A chips the probes that were absent across all chips were removed and subjected to t-test to identify differentially expressed genes. The data set was annotated using Entrez Gene and full annotation files NetAffy software and probe sets were consolidated based on Entrez Gene ID and subjected to microarray.dog.MetaAnalysisTester. The analysis keeps one probe for each gene with the smallest p-value for up or down t-test. The probe with smallest p-value for up regulated genes may be different from probe sets with smallest p-value for down-regulated genes. When the data from U95A and U133A was combined if a gene was represented on one platform, but not on both the missing data was replaced with NA. The data was subjected to Fisher combine p-values using inverse chi-square method and permutation test to determine new p-value, named randomized inverse chi-square $\mathrm{p}$-value and to calculate the traditional inverse chi-square p-value. The false discovery rate was calculated using the inverse chi-square pvalue and the min t-test p-value for each gene.

\section{Quantitative realtime PCR}

The same total RNA isolated from these tissues and used for microarray studies was also subjected to quantitative realtime PCR using custom-made TaqMan Low Density Arrays (LDAs) assessing the expression of 12 genes and the house-keeping gene, GAPDH. Detailed descriptions of LDA and realtime PCR, including data analysis has been provided in the accompanied manuscript[17].

\section{Results}

Gene expression profiles of leiomyomas, keloids and scars Utilizing Affymetrix U133A platform we first assessed the gene expression profile of keloids and incisional scars. Following supervised and unsupervised assessments of the gene expression values in each cohort the combined data set with the gene expression values of leiomyomas reported in the accompanying manuscript using U133A arrays [17] only for the purpose of comparative analysis. The analysis based on supervised and unsupervised assessment and $\mathrm{P}$ ranking of $\mathrm{P}<0.005$, followed by 2 -fold cutoff change selection, resulted in identification of 1124 transcripts (1103 genes) of which 732 genes were overexpressed and 371 were under-expressed in leiomyomas as compared to keloids/incisional scars $(\mathrm{N}=4)$. Hierarchical clustering separated these genes into distinctive groups with each cohort clustering into the corresponding subgroup (Fig. 1). A partial list of these differentially expressed genes with their biological functions is shown in Tables 1 and 2. The combined gene list presented in Tables 1 and 2 is different from the list reported in the accompanying manuscript for leiomyomas[17], although many commonly expressed genes displaying different expression values could be find in between the tables.

The analysis based on inclusion of leiomyomas as two independent cohorts ( 3 A. American and 3 Caucasians) resulted in identification of a limited number of differentially expressed genes as compared to keloids $(\mathrm{N}=2)$ /incisional scars $(\mathrm{N}=2)$. Because both keloids were from $\mathrm{A}$. American patients we excluded one of the incisional scar from a Caucasian patient from the analysis and lowered the statistical stringency to $\mathrm{P}<0.01$ which resulted in identified 424 differentially expressed genes in A. American leiomyomas as compared to keloids/scars. Similar analysis resulted in identified 393 differentially expressed genes in Caucasian leiomyomas as compared to keloids/ scars (all from A. Americans). Of these genes 64 and 32 genes, respectively differed by at least 2 fold in leiomyomas of AA and Caucasians, compared to keloids/incisional scars (Table 3).

We also utilized the gene expression values obtained in our previous microarray studies in leiomyomas[11] and peritoneal adhesions (unpublished results) for comparative analysis. Because these results were generated using Affymetrix U95A GeneChips, due to cross-platform comparability with U133A the combined data from both platforms were subjected to additional analysis as described in the materials and methods. The analysis based on $\mathrm{p}<$ 0.005 and 2-fold change cutoff identified 1801 genes as over-expressed and 45 under-expressed in leiomyomas as compared to keloids/incisional scars and peritoneal adhesions (considered as one cohort during analysis). Of these, 85 genes were differentially expressed in leiomyo- 


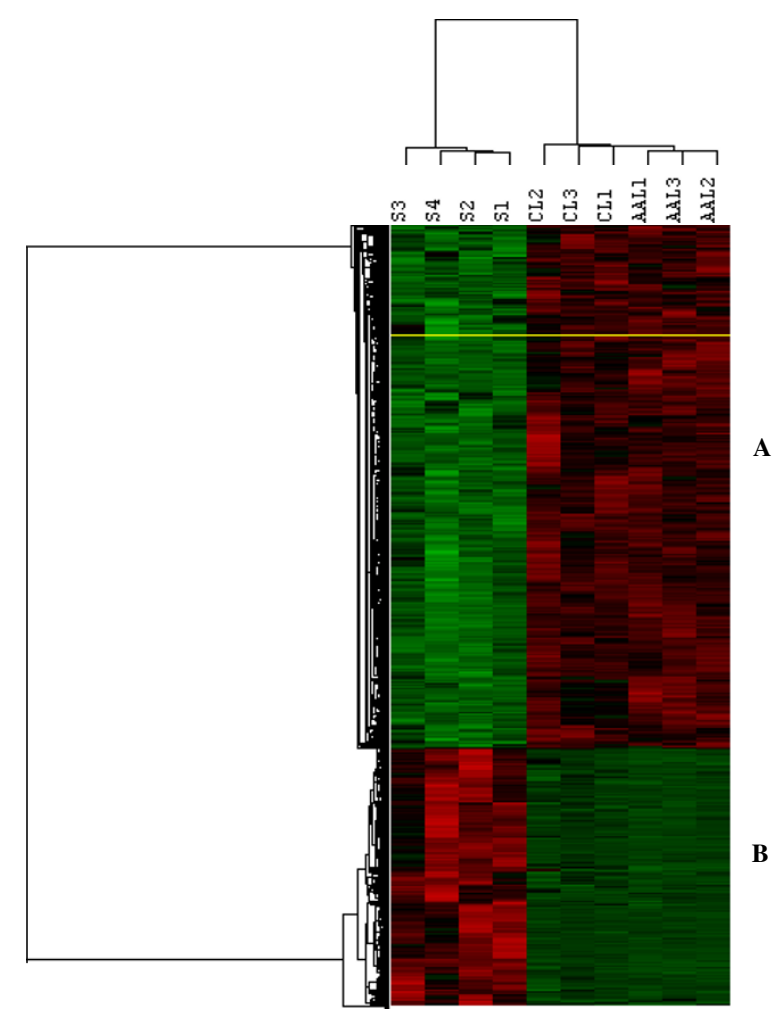

\section{Figure I}

Cluster analysis of I I 24 differentially expressed transcripts in leiomyomas $(N=6)$ form African Americans ( $A A L I, A A L 2$ and AAL3), Caucasians (CLI, CL2, and CL3) and in keloids (S3 and S4) and incisional scars (SI and S2) identified following supervised and unsupervised analysis and $\mathrm{p}$ ranking of $\mathrm{P}<$ 0.005 followed by 2 -fold cutoff change selection (Affymetrix UI33A). Genes represented by rows were clustered according to their similarities in expression patterns for each tissue identified as $A$ and $B$. The dendrogram displaying similarity of gene expression among the cohorts is shown on top of the image, and relatedness of the arrays is denoted by distance to the node linking the arrays. The incisional scar (SI) and keloids were from African American patients. The shade of red and green indicates up- or down-regulation of a given gene according to the color scheme shown below.

mas as compared to peritoneal adhesions (Fig. 2), however exclusion of U133A data from the analysis resulted in identification of a higher number differentially expressed genes. The gene expression profiles in these tissues were comparatively analyzed with their corresponding normal tissues, myometrium, skin and peritoneum, and as expected they displayed distinct patterns (data not shown). The analysis confirmed the effect of cross-platform on gene expression profiling when comparing results of different studies (See Nature Bio-technology, Sept 2006 for several reviews).

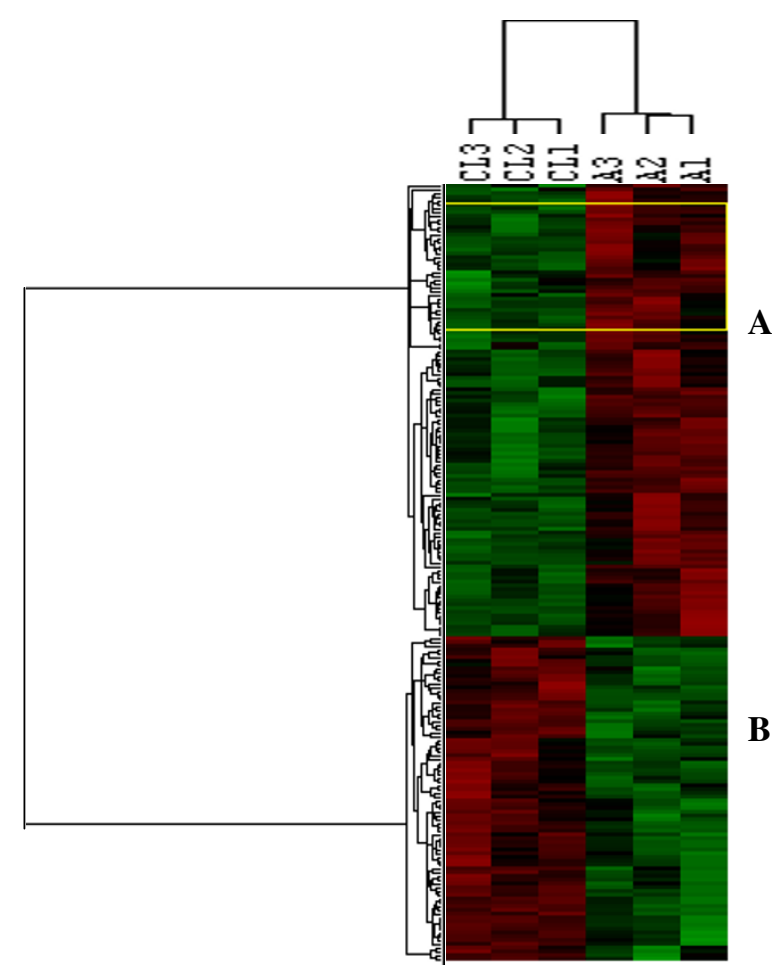

Figure 2

Cluster analysis of 206 differentially expressed genes in leiomyomas from Caucasians (CLI, CL2, and CL3) and peritoneal adhesions (AI, A2, A3) using Affymetrix U95 array. The genes were selected based on supervised and unsupervised assessment and $p$ ranking at $P<0.01$ followed by 2 -fold cutoff change selection. The genes represented by rows were clustered according to their similarities in expression patterns for each tissue and identified as $A$ and $B$.

\section{Realtime PCR of gene expression}

Gene ontology assessment and division into functional categories indicated that a majority of the differentially expressed genes identified in these cohorts serve as regulator of transcription, cell cycle and apoptosis, extracellular matrix turnover, adhesion molecules, signal transduction and transcription factors (Tables 1, 2 and 3). Since the expression of E2F1, RUNX3, EGR3, TBPIP, ECM-2, ESM1, THBS1, GAS1, ADAM17, CST6, FBLN5, and COL18A1 was evaluated in leiomyomas using LDA-based realtime PCR as described in the accompanying manuscript [17] we used the same approach and compared their expression in keloids, incisional scars and peritoneal adhesions. The level of expression of these 12 genes displayed significant variations among these tissues with some overlapping patterns with the microarray results. By setting the mean expression value of each gene independently as 1 in leiomyomas compared with their mean expression in keloids/incisional scars (scar) and adhesions, the results 
indicated that the expression of E2F1, TBPIP and ESM1 was elevated in leiomyoma as compared to keloids/incisional scars and adhesions (Fig. 3, P < 0.05). In contrast, the expression of EGR3, ECM2, THBS1, GAS1 and FBLN5 in scars and RUNX3 and COL18 expression in peritoneal adhesions was higher as compared to leiomyomas (Fig. 3).

\section{Discussion}

Using a large-scale gene expression profiling approach we compared leiomyomas with keloids, incisional cars and peritoneal adhesions and found that their molecular environments consist of a combination of both tissue-specific and commonly expressed genes. The tissue-specific gene expression between leiomyomas and keloids was not reflected based on the presence/absence of unique genes, but rather occurred at the level of expression of a selective number of differentially expressed genes. As such an elevated level of expression of a number of muscle cell-specific genes in leiomyomas and fibroblast-specific genes in keloids reflected the specific cellular make up of these tissues. In addition, specific expression of estrogen receptor (ER) in leiomyomas with limited expression in keloids and incesional scar tissues re-enforced the importance of ovarian steroids in leiomyomas growth. Collectively the results suggest that the molecular environments that govern the characteristic of these fibrotic tissues, at least at genomic levels, are relatively similar and involved specific set of genes represented by 3 to $12 \%$ of the genes on the array. This observation also suggests that differential expression of a limited number of these genes with unique biological functions may regulate the processes that results in establishment and progression of leiomyoma, keloids, incisional scars, and possibly other fibrotic disorders, despite differences in the nature of their development and growth.

We recognize that the stage of the menstrual cycle and to a limited extend the size of leiomyomas, as well as the period since keloids, incisional scars and peritoneal adhesions were first formed, reflecting the stage of wound healing, influences the outcome of their gene expression. Although leiomyomas used in our study were similar in size and from the same phase of the menstrual cycle, the stage of keloids and scars tissues was unknown. As such the study results represent their gene expression at the time of collection. We also recognize that small sample size limited our ability to analyze the data based on ethnicity, because of more frequent development of leiomyomas and keloids in African Americans. However, it is worth mentioning that comparing leiomyomas with keloids from this ethnic group showed a limited difference in their gene expression profile, or when compared with leiomyomas from Caucasians, suggesting the existence of a comparable environment in leiomyomas and keloids.
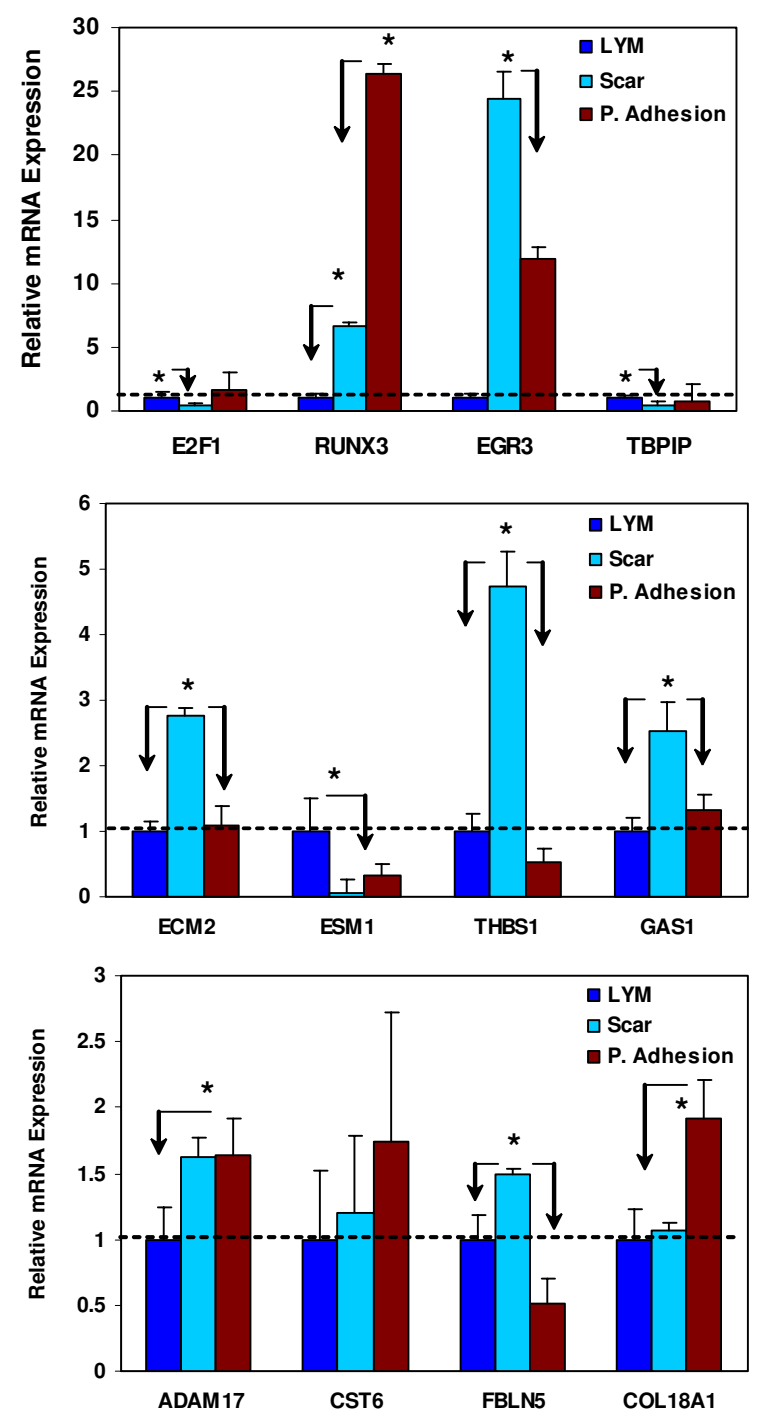

\section{Figure 3}

The bar graphs show the relative mean expression levels of 12 genes (E2FI, RUNX3, EGR3, TBPIP, ECM-2 ESMI, THBSI, GASI, ADAMI7, CST6, FBLN5, and COLI8AI) in leiomyomas (LYM), keloids/incisional scars (Scar) and peritoneal adhesions ( $P$. Adhesion) using realtime PCR and LDA as described in materials and methods section. Values on the $y-$ axis represent an arbitrary unit derived from the mean expression level of these genes in each tissue with their mean expression values in leiomyomas set at I independently for each gene prior to normalization against their expression levels in myometrium form a Caucasian serving as control. The asterisks * indicate statistical difference between the expression of these genes with arrows pointing the difference between each group. A probability level of $P<0.05$ was considered significant. 
Table 2: List of under-expressed in leiomyomas as compared to scar tissues (keloids/incesional scars)

\begin{tabular}{|c|c|c|c|c|}
\hline Gene Bank & Symbol & Fold Change & Probability & Function \\
\hline AF004709 & MAPKI3 & 0.06 & 0.0002 & apoptosis \\
\hline AF010316 & PTGES & 0.09 & 0.0003 & apoptosis \\
\hline NM 014430 & CIDEB & 0.21 & 0.0014 & apoptosis \\
\hline A)307882 & TRADD & 0.26 & 0.0007 & apoptosis \\
\hline BC041689 & CASPI & 0.31 & 0.0009 & apoptosis \\
\hline NM 014922 & NALPI & 0.31 & 0.0025 & apoptosis \\
\hline AFI59615 & FRAGI & 0.33 & 0.0044 & apoptosis \\
\hline BC019307 & $\mathrm{BCL} 2 \mathrm{LI}$ & 0.42 & 0.0027 & apoptosis \\
\hline NM 016426 & GTSEI & 0.43 & 0.0033 & apoptosis \\
\hline AK027080 & LTBR & 0.50 & 0.0047 & apoptosis \\
\hline M92287 & CCND3 & 0.48 & 0.0028 & cell cycle \\
\hline A) 242501 & MAP7 & 0.2 & 0.0001 & structural molecule \\
\hline AF381029 & LMNA & 0.3 & 0.00001 & structural molecule \\
\hline$\times 83929$ & DSC3 & 0.009 & 0.0035 & cell adhesion \\
\hline AB025105 & $\mathrm{CDHI}$ & 0.01 & 0.0009 & cell adhesion \\
\hline$\overline{\mathrm{A} / 246000}$ & SELL & 0.21 & 0.002 & cell adhesion \\
\hline NM 003568 & ANXA9 & 0.22 & 0.0031 & cell adhesion \\
\hline AF281287 & PECAMI & 0.36 & 0.0017 & cell adhesion \\
\hline 100124 & KRTI4 & 0.0001 & 0.0003 & cytoskeleton/motility \\
\hline BC034535 & KRT6B & 0.005 & 0.0043 & cytoskeleton/motility \\
\hline M19156 & KRTIO & 0.018 & 0.001 & cytoskeleton/motility \\
\hline A)551176 & $\mathrm{SDCl}$ & 0.039 & 0.0038 & cytoskeleton/motility \\
\hline NM 006478 & GAS2LI & 0.22 & 0.0016 & cytoskeleton/motility \\
\hline M34225 & KRT8 & 0.26 & 0.0029 & cytoskeleton/motility \\
\hline NM 005886 & KATNBI & 0.27 & 0.0011 & cytoskeleton/motility \\
\hline AK024835 & CNN2 & 0.47 & 0.003 & cytoskeleton/motility \\
\hline NM 006350 & FST & 0.11 & 0.00001 & extracellular matrix \\
\hline AFI7794I & COLSA3 & 0.14 & 0.00001 & extracellular matrix \\
\hline$\underline{\mathbf{L} 22548}$ & COLI8AI & 0.49 & 0.0011 & extracellular matrix \\
\hline M5805I & FGFR3 & 0.007 & 0.0039 & growth factor receptor \\
\hline NM 004887 & $\mathrm{CXCLI} 4$ & 0.009 & 0.0014 & chemokine \\
\hline AF289090 & BMP7 & 0.13 & 0.002 & cytokine \\
\hline$\underline{\mathrm{K} 03222}$ & TGFA & 0.2 & 0.0048 & growth factor \\
\hline M31682 & INHBB & 0.20 & 0.00001 & cytokine \\
\hline NM 004750 & CRLFI & 0.26 & 0.0003 & cytokine binding \\
\hline NM 002514 & NOV (CCN3) & 0.28 & 0.0009 & growth factor \\
\hline NM 000685 & AGTRI & 0.30 & 0.005 & growth factor receptor \\
\hline D16431 & HDGF & 0.42 & 0.0046 & creatine kinase \\
\hline L36719 & MAP2K3 & 0.22 & 0.0048 & protein kinase activity \\
\hline A) 290975 & ITPKC & 0.28 & 0.0036 & protein kinase activity \\
\hline NM 001569 & IRAKI & 0.33 & 0.0001 & protein kinase activity \\
\hline AB025285 & ERBB2 & 0.45 & 0.0003 & protein kinase \\
\hline$\overline{\text { AF029082 }}$ & SFN & 0.001 & 0.0028 & signal transduction \\
\hline AB065865 & HM74 & 0.04 & 0.0047 & signal transduction \\
\hline AA021034 & LTB4R & 0.06 & 0.0006 & signal transduction \\
\hline NM 004445 & EPHB6 & 0.12 & 0.0038 & signal transduction \\
\hline AF025304 & EPHB2 & 0.17 & 0.0021 & signal transduction \\
\hline $\mathrm{AB} 026663$ & $M C I R$ & 0.17 & 0.0046 & signal transduction \\
\hline AF035442 & VAV3 & 0.17 & 0.004 & signal transduction \\
\hline NM 014030 & GITI & 0.21 & 0.0025 & signal transduction \\
\hline $\mathrm{ABO} 11152$ & CENTDI & 0.21 & 0.0003 & signal transduction \\
\hline AK095244 & CYB56I & 0.23 & 0.0001 & signal transduction \\
\hline AFI06858 & GPR56 & 0.23 & 0.0002 & signal transduction \\
\hline AF231024 & CELSRI & 0.23 & 0.0006 & signal transduction \\
\hline$\overline{\mathrm{AF} 234887}$ & CELSR2 & 0.24 & 0.0003 & signal transduction \\
\hline NM 007197 & FZDIO & 0.25 & 0.0009 & signal transduction \\
\hline NM 014349 & APOL3 & 0.25 & 0.002 & signal transduction \\
\hline NM 004039 & ANXA2 & 0.27 & 0.0044 & signal transduction \\
\hline Al285986 & THBD & 0.29 & 0.0004 & signal transduction \\
\hline M57730 & EFNAI & 0.31 & 0.0032 & signal transduction \\
\hline NM 002118 & HLA-DMB & 0.33 & 0.0008 & signal transduction \\
\hline AF427491 & TUBB4 & 0.36 & 0.001 & signal transduction \\
\hline NM 005279 & GPRI & 0.40 & 0.0033 & signal transduction \\
\hline$\times 60592$ & TNFRSF5 & 0.40 & 0.0032 & signal transduction \\
\hline BC052968 & EPHB3 & 0.42 & 0.0001 & signal transduction \\
\hline M64749 & CMKORI & 0.46 & 0.0014 & signal transduction \\
\hline$M 21188$ & IDE & 0.46 & 0.0031 & signal transduction \\
\hline ABO18325 & CENTD2 & 0.47 & 0.0004 & signal transduction \\
\hline
\end{tabular}


Table 2: List of under-expressed in leiomyomas as compared to scar tissues (keloids/incesional scars) (Continued)

\begin{tabular}{|c|c|c|c|c|}
\hline AK054968 & ITGB5 & 0.49 & 0.0005 & signal transduction \\
\hline NM 001730 & KLF5 & 0.04 & 0.0021 & transcription factor \\
\hline NM 004350 & RUNX3 & 0.08 & 0.0001 & transcription factor \\
\hline$\underline{\text { U34070 }}$ & CEBPA & 0.11 & 0.0005 & transcription factor \\
\hline AF062649 & PTTGI & 0.15 & 0.0039 & transcription factor \\
\hline NM 004235 & KLF4 & 0.20 & 0.0005 & transcription factor \\
\hline$\underline{\times 52773}$ & $R \times R A$ & 0.20 & 0.0011 & transcription factor \\
\hline$\underline{A F 202118}$ & HOXDI & 0.21 & 0.0006 & transcription factor \\
\hline NM 000376 & VDR & 0.21 & 0.0001 & transcription factor \\
\hline NM_006548 & IMP-2 & 0.26 & 0.0031 & transcription factor \\
\hline NM 007315 & STATI & 0.32 & 0.00001 & transcription factor \\
\hline NM 004430 & EGR3 & 0.34 & 0.002 & transcription factor \\
\hline NM 003644 & GAS7 & 0.36 & 0.0033 & transcription factor \\
\hline NM_005900 & MADHI & 0.48 & 0.0028 & transcription factor \\
\hline$\underline{X 14454}$ & IRFI & 0.49 & 0.0013 & transcription factor \\
\hline AF067572 & STAT6 & 0.49 & 0.0001 & transcription factor \\
\hline NM 005596 & NFIB & 0.49 & 0.0041 & transcription factor \\
\hline $\mathrm{AB} 002282$ & EDFI & 0.40 & 0.0002 & transcription coactivator \\
\hline AK075393 & CTSB & 0.50 & 0.0016 & protease activity \\
\hline $\mathrm{AB} 021227$ & MMP24 & 0.29 & 0.0001 & protease activity \\
\hline AB007774 & CSTA & 0.02 & 0.0018 & cysteine protease inhibitor \\
\hline AFI43883 & ALOXI2 & 0.06 & 0.0016 & catalytic activity \\
\hline AF440204 & PTGSI & 0.08 & 0.00001 & catalytic activity \\
\hline NM 000777 & CYP3A5 & 0.14 & 0.0041 & catalytic activity \\
\hline NM 016593 & CYP39AI & 0.21 & 0.0027 & catalytic activity \\
\hline BC001491 & HMOXI & 0.23 & 0.0028 & catalytic activity \\
\hline$\underline{\mathrm{BC} 020734}$ & PGDS & 0.26 & 0.00001 & catalytic activity \\
\hline$\underline{A L I 33324}$ & GSS & 0.39 & 0.002 & catalytic activity \\
\hline AF055027 & CARMI & 0.41 & 0.00001 & catalytic activity \\
\hline NM_001630 & ANXA8 & 0.01 & 0.0006 & calcium ion binding \\
\hline$\underline{A B 011542}$ & EGFL5 & 0.43 & 0.0001 & calcium ion binding \\
\hline NM 005979 & SIOOAI3 & 0.31 & 0.001 & calcium ion binding \\
\hline NM 020672 & SI00AI4 & 0.02 & 0.0005 & calcium ion binding \\
\hline NM_005978 & $\mathrm{SIOOA} 2$ & 0.003 & 0.005 & calcium ion binding \\
\hline$\underline{\mathrm{BC} 012610}$ & $\mathrm{HFI}$ & 0.22 & 0.00001 & complement activation \\
\hline AF052692 & GJB3 & 0.03 & 0.0001 & connexon channel activity \\
\hline MI2529 & APOE & 0.21 & 0.0001 & metabolism \\
\hline NM_004925 & AQP3 & 0.01 & 0.0003 & transporter activity \\
\hline
\end{tabular}

Partial list of differentially expressed genes identified in leiomyomas (African Americans and Caucasians) as compared to keloid/incisional scars as shown in Fig. I. The genes were selected based on p ranking of $p \leq 0.005$ and 2 -fold cutoff change selection ( $F$. Change) as described in materials and methods. Table 2 displays the under-expressed genes in leiomyomas as compared to keloid/incisional scars.

Further comparison of leiomyomas' gene expression with peritoneal adhesions (Affymetrix U95A subjected to crossplatform comparability analysis) also identified a low number of differentially expressed genes (85 genes) in these tissues, although analysis based only on U95A arrays identified higher numbers. The results indicate that the molecular environment of leiomyomas may be more comparable to peritoneal adhesions as compared to keloids/incisional scars at least at late stage of their wound healing development. Possibly the size of leiomyomas (larger size often undergoing degeneration at the center), and the stage of keloids, incesional scars and adhesions formation following tissue injury influencing their gene expression profiles would produce different results from our study and their evaluation would enhance our understanding of molecular conditions that lead to tissue fibrosis at these and other sites [18-21].

A majority of the genes identified in leiomyomas, keloid, incisional scars and adhesions function as regulators of cell survival (cell cycle and apoptosis), cell and tissue structure (ECM, adhesion molecules and cytoskeleton), tissue turnover, inflammatory mediators, signal transduction and transcription and metabolism. Consistent with the importance of ECM, cytoskeleton, adhesion molecules and proteases in tissue fibrosis we identified the expression of many of genes in these categories some with 5 to 60 fold increase in their expression. Elevated expression of DES, MYH11, MYL9 and SMTN in leiomyomas and several KRTs in keloids and scars reflects the cellular composition of these tissues. Additionally, PALLD has been considered to serve as a novel marker of myofibroblast conversion and is regulated by profibrotic cytokine such as TGF- $\beta[22,23]$. SM22, which is overexpressed in keloids[24], promotes ECM accumulation through inhibition of MMP-9 expression [25]. The expression of many components of ECM including collagens, decorin, versican, fibromodulin, intergrins, extracellular matrix protein 1 (ECM-1), syndecan and ESM-1 has been identified in leiomyomas $[11,17,26]$ as well as dermal wounds during healing, scars and keloids (for review see [27-32]).We validated the expression of ECM-2, ESM1, THBS1, FBLN5 
Table I: List of over-expressed in leiomyomas as compared to scar tissues (keloids/incesional scars)

\begin{tabular}{|c|c|c|c|c|}
\hline Gene Bank & Symbol & Fold Change & Probability & Function \\
\hline NM 003478 & CUL5 & 5.06 & 0.0001 & apoptosis \\
\hline $\mathrm{AB} 037736$ & CASP8AP2 & 4.07 & 0.0021 & apoptosis \\
\hline NM 018947 & CYCS & 2.08 & 0.0013 & apoptosis \\
\hline $\mathrm{AB} 014517$ & CUL3 & 2.07 & 0.00001 & apoptosis \\
\hline $\mathrm{BC} 010958$ & CCND2 & 5.62 & 0.0041 & cell cycle \\
\hline$\underline{U} 47413$ & CCNGI & 3.16 & 0.0007 & cell cycle \\
\hline AF048731 & $\mathrm{CCNT2}$ & 2.83 & 0.0004 & cell cycle \\
\hline NM 001927 & DBS & 61.51 & 0.0022 & cytoskeleton/motility \\
\hline AK 124338 & ACTG2 & 30.16 & 0.00001 & cytoskeleton/motility \\
\hline $\mathrm{BC} 022015$ & CNNI & 27.26 & 0.00001 & cytoskeleton/motility \\
\hline NM 006449 & CDC42EP3 & 25.29 & 0.0051 & cytoskeleton/motility \\
\hline $\mathrm{AB} 023209$ & KIAA0992 & 17.61 & 0.0004 & cytoskeleton/motility \\
\hline AF474I56 & TPMI & 14.84 & 0.0029 & cytoskeleton/motility \\
\hline $\mathrm{BC} 011776$ & TPM2 & 12.04 & 0.00001 & cytoskeleton/motility \\
\hline M11315 & COL4AI & 11.87 & 0.0029 & cytoskeleton/motility \\
\hline AK 126474 & LMODI & 9.49 & 0.00001 & cytoskeleton/motility \\
\hline $\mathrm{AB} 062484$ & CALDI & 9.22 & 0.0042 & cytoskeleton/motility \\
\hline NM 003186 & TAGLN & 6.68 & 0.00001 & cytoskeleton/motility \\
\hline$\overline{\mathrm{BC} 017554}$ & ACTA2 & 5.18 & 0.00001 & cytoskeleton/motility \\
\hline AK074048 & FLNA & 5.08 & 0.00001 & cytoskeleton/motility \\
\hline NM 016274 & CKIP-I & 4.44 & 0.002 & cytoskeleton/motility \\
\hline $\mathrm{BC} 003576$ & ACTNI & 4.23 & 0.0024 & cytoskeleton/motility \\
\hline AF08984I & FLNC & 3.43 & 0.0005 & cytoskeleton/motility \\
\hline$\times 05610$ & COL4A2 & 7.86 & 0.0017 & extracellular matrix \\
\hline $\mathrm{BC} 005159$ & COL6AI & 3.70 & 0.002 & extracellular matrix \\
\hline A98730 & CAPN6 & 13.7 & 0.0023 & protease activity \\
\hline$\underline{U} 41766$ & ADAM9 & 4.76 & 0.0021 & protease \\
\hline NM 001110 & ADAMIO & 3.2 & 0.00001 & protease \\
\hline $\mathrm{AF031385}$ & CYR6I (CCNI) & 9.13 & 0.0035 & growth factor \\
\hline M32977 & VEGF & 7.13 & 0.002 & growth factor \\
\hline AF035287 & SDFRI & 4.70 & 0.0001 & chemokine receptor \\
\hline$\times 04434$ & IGFIR & 3.64 & 0.0017 & growth factor receptor \\
\hline $\mathrm{AB} 029156$ & HDGFRP3 & 2.89 & 0.0006 & GF receptor activity \\
\hline AF056979 & IFNGRI & 2.72 & 0.0001 & signal transduction \\
\hline $\mathrm{AB} 020673$ & MYHII & 53.80 & 0.0006 & signal transduction \\
\hline $\mathrm{D} 26070$ & ITPRI & 26.18 & 0.0034 & signal transduction \\
\hline $\mathrm{AB} 037717$ & SORBSI & 15.25 & 0.0005 & signal transduction \\
\hline $\mathrm{AFI} 10225$ & ITGBIBP2 & 14.18 & 0.0009 & signal transduction \\
\hline $\mathrm{AB} 004903$ & SOCS2 & 11.39 & 0.0002 & signal transduction \\
\hline B0III47 & GREBI & 11.37 & 0.0025 & signal transduction \\
\hline $\mathrm{AB} 000509$ & TRAF5 & 7.83 & 0.0032 & signal transduction \\
\hline NM 005261 & GEM & 7.48 & 0.0003 & signal transduction \\
\hline AF028832 & HSPCA & 4.27 & 0.00001 & signal transduction \\
\hline$\overline{A C 006581}$ & M6PR & 3.85 & 0.0012 & signal transduction \\
\hline AF275719 & HSPCB & 3.74 & 0.001 & signal transduction \\
\hline A) 242780 & ITPKB & 3.68 & 0.00001 & signal transduction \\
\hline AK095866 & GPRI25 & 3.62 & 0.0001 & signal transduction \\
\hline AFOI6050 & NRPI & 3.44 & 0.0011 & signal transduction \\
\hline$\overline{\mathrm{AB} 015706}$ & IL6ST & 3.42 & 0.0002 & signal transduction \\
\hline AK057I20 & HMGBI & 3.16 & 0.0001 & signal transduction \\
\hline NM 006644 & HSPHI & 3.14 & 0.002 & signal transduction \\
\hline $\mathrm{AB} 072923$ & BSG & 2.90 & 0.0024 & signal transduction \\
\hline $\mathrm{ABO} 10881$ & FZD7 & 2.62 & 0.0024 & signal transduction \\
\hline AF273055 & INPP5A & 2.58 & 0.002 & signal transduction \\
\hline $\mathrm{AC078943}$ & TANK & 2.32 & 0.0005 & signal transduction \\
\hline AF05I344 & LTBP4 & 2.20 & 0.0002 & signal transduction \\
\hline A) 404847 & ILK & 4.74 & 0.0002 & protein kinase activity \\
\hline AFII991I & CSNKIAI & 3.40 & 0.0015 & protein kinase activity \\
\hline NM 002037 & FYN & 3.30 & 0.0028 & protein kinase activity \\
\hline $\mathrm{AB} 058694$ & CDC2L5 & 2.37 & 0.0001 & protein kinase activity \\
\hline AF4I5I77 & CAMK2G & 2.18 & 0.0008 & protein kinase activity \\
\hline NM 005654 & $\mathrm{NR} 2 \mathrm{FI}$ & 12.57 & 0.0039 & transcription factor \\
\hline $\mathrm{BC} 062602$ & PNN & 9.93 & 0.0001 & transcription factor \\
\hline AK098I74 & MEISI & 9.61 & 0.00001 & transcription factor \\
\hline$\overline{N M \quad 000125}$ & ESRI & 9.36 & 0.0004 & transcription factor \\
\hline AF249273 & BCLAFI & 8.62 & 0.0001 & transcription factor \\
\hline AF017418 & MEIS2 & 7.46 & 0.0009 & transcription factor \\
\hline AF045447 & $\mathrm{MADH} 4$ & 6.39 & 0.00001 & transcription factor \\
\hline
\end{tabular}


Table I: List of over-expressed in leiomyomas as compared to scar tissues (keloids/incesional scars) (Continued)

\begin{tabular}{|c|c|c|c|c|}
\hline AFI62704 & AR & 5.54 & 0.0018 & transcription factor \\
\hline NM 001527 & HDAC2 & 4.76 & 0.00001 & transcription factor \\
\hline NM 004268 & CRSP6 & 4.76 & 0.0001 & transcription factor \\
\hline BC020868 & STAT5B & 4.57 & 0.0003 & transcription factor \\
\hline $\mathrm{BC} 002646$ & JUN & 3.84 & 0.0042 & transcription factor \\
\hline AY347527 & CREBI & 3.77 & 0.0031 & transcription factor \\
\hline AL833643 & MAX & 3.66 & 0.0014 & transcription factor \\
\hline NM 021809 & TGIF2 & 3.58 & 0.0014 & transcription factor \\
\hline$\underline{\mathrm{AB} 007836}$ & TGFBIII & 3.55 & 0.0007 & transcription coactivator \\
\hline NM_005760 & CEBPZ & 3.53 & 0.00001 & transcription factor \\
\hline AL833268 & MEF2C & 3.49 & 0.0019 & transcription factor \\
\hline NM 005903 & MADH5 & 3.10 & 0.0037 & transcription factor \\
\hline NM 022739 & SMURF2 & 2.58 & 0.0013 & transcription factor \\
\hline NM_003472 & DEK & 2.55 & 0.0001 & transcription factor \\
\hline NM 001358 & $\mathrm{DH} \times \mathrm{I5}$ & 2.49 & 0.0029 & transcription factor \\
\hline $\mathrm{BC} 029619$ & ATFI & 2.41 & 0.0026 & transcription factor \\
\hline AB082525 & $\mathrm{TSC} 22$ & 2.26 & 0.0002 & transcription factor \\
\hline AL83।995 & MEF2A & 2.25 & 0.0024 & transcription factor \\
\hline AA765457 & DDXI7 & 10.41 & 0.0035 & translation factor \\
\hline NM 018951 & HOXAIO & 8.69 & 0.00001 & translation factor \\
\hline BC00075I & EIF5A & 4.07 & 0.001 & translation factor \\
\hline AFOI5812 & DDX5 & 2.48 & 0.0004 & translation factor \\
\hline AL079283 & EIFIA & 2.35 & 0.0005 & translation factor \\
\hline NM 003760 & EIF4G3 & 2.35 & 0.0028 & translation factor \\
\hline NM 012218 & ILF3 & 2.29 & 0.0003 & translation factor \\
\hline ABOI8284 & EIF5B & 2.26 & 0.002 & translation factor \\
\hline AFI55908 & HSPB7 & 9.52 & 0.0002 & protein binding \\
\hline AF209712 & MCP & 6.54 & 0.00001 & complement activation \\
\hline AL833430 & SPARCLI & 5.12 & 0.00001 & calcium ion binding \\
\hline AF297048 & PTGIS & 4.26 & 0.0004 & catalytic activity \\
\hline AF288537 & FSTLI & 4.11 & 0.001 & calcium ion binding \\
\hline AB03495I & HSPA8 & 3.13 & 0.001 & protein binding \\
\hline NM 001155 & ANXA6 & 2.85 & 0.0014 & calcium ion binding \\
\hline NM_003642 & HATI & 2.81 & 0.00001 & catalytic activity \\
\hline NM 002267 & KPNA3 & 2.55 & 0.0031 & protein transporter \\
\hline AKI24769 & XPOI & 2.46 & 0.0002 & protein transporter \\
\hline A) 238248 & CENTB2 & 2.37 & 0.0045 & GTPase activator activity \\
\hline AF072928 & MTMR6 & 2.17 & 0.002 & phosphatase activity \\
\hline
\end{tabular}

Partial list of differentially expressed genes identified in leiomyomas (African Americans and Caucasians) as compared to keloid/incisional scars as shown in Fig. I. The genes were selected based on p ranking of $p \leq 0.005$ and 2 -fold cutoff change selection (F. Change) as described in materials and methods. Table I displays the over-expressed genes in leiomyomas as compared to keloid/incisional scars.

and COL18A1 in keloids, incisional scars and adhesions and the analysis indicated an elevated expression of ECM2, THBS1 and FBLN5 in keloid/incisional scars and COL18 in peritoneal adhesions as compared to leiomyomas[17]. Although the biological significance of these gene products and changes in their expression in leiomyomas, keloids and adhesions remains to be established, the product of a specific number of these genes such as ECMs, THBS1, FBLNs, MMPs and ADAMs play a critical role in various aspect of wound healing and tissue fibrosis [27-32]. A number of MMPs were equally expressed in leiomyomas, keloids and peritoneal adhesions with the exception of lower MMP-14, MMP-24 and MMP-28 expression in leiomyomas, suggesting that these tissues are potential target of their proteolytic actions. The biological importance of lower expression of these MMPs in leiomyoma is unknown; however unlike most MMPs that are secreted as inactive proenzymes and require activation, MMP-11 and MMP-28 are secreted in active forms. In keratinocytes, MMP-28 is expressed in response to injury and detected in the conditioned media of hypertrophic scars, but not normotrophic scars [33]. A lower expression of MMP-28 and elevated expression of TIMP-3 in leiomyomas compared to keloids imply a lower matrix turnover with an increase angiogenic and pro-apoptotic activities that has been associated with TIMP-3 [34,35].

We identified an overexpression of a higher number of apoptotic-related genes in keloids and incisional scars as compared to leiomyomas, suggesting an increased rate of cellular turnover. Because apoptotic and non-apoptotic cell death is considered to increase local inflammatory reaction and a key step in tissue fibrosis, a number of genes functionally categorized as proinflammatory and pro-fibrotic mediators were identified in these tissues. Noticeable among these genes were TGF- $\beta$, IL-1, IL-6, IL11, IL-13, IL-17, IL-22 and IL-27 and chemokines CCL-2 to 5, CX3-CL1, CXCL-1, CXCL-12 and CXCL-14 and their receptors. Elevated expression of PDGF-C, VEGF and FGF2 in leiomyomas as compared to keloids and adhesions imply an additional role for these angiogenic factors in pathogenesis of leiomyomas. While the expression of TGF- $\beta$ was equally elevated in leiomyomas, keloids, incisional scars and peritoneal adhesion as compared to their 
Table 3: Differentially expressed genes in leiomyomas compared to keloids/incesional scars

\begin{tabular}{|c|c|c|c|c|c|}
\hline Gene Bank & Symbol & $\begin{array}{l}\text { F. Change } \\
\text { LAA:Scar }\end{array}$ & $\begin{array}{l}\text { F. Change } \\
\text { LC:Scar }\end{array}$ & $P$ value & Function \\
\hline NM 006198 & PCP4 & 68.14 & 6.66 & 0.0017 & system development \\
\hline$\underline{S 67238}$ & MYOSIN & 62.78 & 36.69 & 0.0034 & cytoskeleton/motility \\
\hline NM 004342 & CaldI & 21.43 & 9.32 & 0.0047 & cytoskeleton/motility \\
\hline NM 013437 & LRPI2 & 20.6 & 6.82 & 0.0053 & cellular process \\
\hline AC004010 & AMIGO2 & 19.07 & 10.61 & 0.0021 & cell adhesion \\
\hline AF040254 & $O C X$ & $|8.7|$ & 5.39 & 0.0099 & signal transduction \\
\hline NM 015385 & SORBSI & 17.44 & 9.26 & 0.0003 & cytoskeleton/motility \\
\hline NM 012278 & ITGBIBP2 & 17.42 & 9.9 & 0.0018 & signal transduction \\
\hline NM 006101 & KNTC2 & 17.33 & 5.23 & 0.0022 & transcription factor \\
\hline NM 001845 & COL4AI & 16.08 & 5.94 & 0.0029 & cytoskeleton/motility \\
\hline AFI04857 & CDC42EP3 & 16.08 & 3.78 & 0.0002 & cytoskeleton/motility \\
\hline AWI8813I & DDXI7 & 15.65 & 9.11 & 0.0005 & translation factor \\
\hline NM 001057 & TACR2 & 15.6 & 4.51 & 0.0062 & signal transduction \\
\hline $\mathrm{Al} 375002$ & ZNF447 & 14.55 & 8.04 & 0.0061 & transcription factor \\
\hline NM 014890 & $\mathrm{DOCl}$ & 14.35 & 5.19 & 0.0002 & proteolysis \\
\hline NM 001784 & CD97 & 13.16 & 6.35 & 0.00004 & signal transduction \\
\hline BFIII 821 & WSBI & 12.34 & 7.36 & 0.0024 & signal transduction \\
\hline AWI52664 & PNN & 12.19 & 8.26 & 0.003 & transcription factor \\
\hline NM 002380 & MATN2 & 11.86 & 5.62 & 0.0011 & extracellular matrix \\
\hline NM 007362 & NCBP2 & 11.38 & 8.04 & 0.0034 & RNA processing \\
\hline AK023406 & Macfl & 8.8 & 4.77 & 0.0041 & ECM signaling \\
\hline AF095192 & BAG2 & 8.01 & 4.34 & 0.0018 & apoptosis \\
\hline NM 004196 & CDKLI & 7.91 & 2.83 & 0.0017 & cell cycle \\
\hline BF5 12200 & MBNL2 & 7.58 & 3.01 & 0.0014 & muscle differentiaon \\
\hline AW0437I3 & Sulfl & 6.9 & 0.78 & 0.0039 & hydrolase activity \\
\hline NM 004781 & VAMP3 & 6.76 & 3.02 & 0.0016 & trafficking \\
\hline All 49535 & STAT5B & 5.62 & 3.94 & 0.0043 & transcription factor \\
\hline NM 016277 & RAB23 & 5.61 & 2.68 & 0.0055 & signal transduction \\
\hline Al582238 & TRAI & 5.13 & 3.46 & 0.0042 & calcium ion binding \\
\hline NM 005722 & ACTR2 & 4.04 & 2.49 & 0.0001 & cytoskeleton/motility \\
\hline AFOI6005 & RERE & 4.02 & 2.87 & 0.008 & transcription factor \\
\hline AL046979 & TNSI & 3.65 & 2.14 & 0.0047 & signal transduction \\
\hline NM 005757 & MBNL2 & 3.57 & 0.84 & 0.0049 & muscle development \\
\hline A) 133768 & LDB3 & 3.3 & 1.53 & 0.0056 & cytoskeleton/motility \\
\hline A 1650819 & CUL4B & 3.04 & 1.59 & 0.0045 & metabolism \\
\hline AL031602 & MTIK & 0.61 & 0.33 & 0.0086 & cadmium ion binding \\
\hline$\underline{\mathrm{U} 85658}$ & TFAP2C & 0.27 & 0.14 & 0.0083 & transcription factor \\
\hline NM 003790 & TNFRSF 25 & 0.19 & 0.11 & 0.007 & apoptosis \\
\hline$\underline{\mathrm{BC} 002495}$ & BAIAP2 & 0.18 & 0.11 & 0.0003 & signal transduction \\
\hline AV691491 & TMEM30B & 0.13 & 0.09 & 0.0093 & cell cycle control \\
\hline Al88994I & COL4A6 & 10.4 & 30.21 & 0.007 & extracellular matrix \\
\hline AW45171I & PBXI & 14.44 & 18.14 & 0.0001 & transcription factor \\
\hline NM 014668 & GREBI & 7.18 & 15.94 & 0.0089 & \\
\hline NM 004619 & TRAF5 & 6.47 & 11.46 & 0.0091 & signal transduction \\
\hline NM 005418 & ST5 & 5.83 & 8.1 & 0.0044 & signal transduction \\
\hline $\mathrm{BC} 00281 \mathrm{I}$ & SUMO2 & 0.47 & 0.83 & 0.0035 & protein binding \\
\hline AV700891 & ETS2 & 0.28 & 0.54 & 0.0082 & transcription factor \\
\hline$\underline{A B 042557}$ & PDE4DIP & 0.2 & 0.39 & 0.0019 & signaling \\
\hline NM 014485 & PGDS & 0.17 & 0.31 & 0.0027 & catalytic activity \\
\hline Al984221 & COL5A3 & 0.08 & 0.17 & 0.0011 & extracellular matrix \\
\hline NM 006823 & PKIA & 0.08 & 0.17 & 0.0034 & Kinase regulator \\
\hline AUI44284 & IRF6 & 0.04 & 0.15 & 0.0026 & transcription factor \\
\hline NM 000962 & PTGSI & 0.06 & 0.11 & 0.0046 & catalytic activity \\
\hline NM 022898 & $B C L I I B$ & 0.05 & 0.09 & 0.0099 & transcription factor \\
\hline NM 001982 & ERBB3 & 0.02 & 0.06 & 0.0066 & signal transduction \\
\hline NM 002705 & PPL & 0.005 & 0.031 & 0.0073 & hydrolase activity \\
\hline NM 001630 & ANXA8 & 0.006 & 0.02 & 0.0079 & calcium ion binding \\
\hline N74607 & AQP3 & 0.006 & 0.02 & 0.0098 & transporter activity \\
\hline NM 000142 & FGFR3 & 0.007 & 0.009 & 0.01 & Growth factor \\
\hline
\end{tabular}

Partial list of differentially expressed genes from several functional categories in leiomyomas from African Americans and Caucasians as compared to keloids/ incesional scars as shown in Fig. 2. The genes were selected based on $p$ ranking of $p \leq 0.01$ and following 2 -fold cutoff change 
normal tissues reinforcing the importance of TGF- $\beta$ as principle mediator of tissue fibrosis [30]. Although profibrotic action of TGF- $\beta$ is reported to involve the induction of CTGF, a member of PDGF family with mitogen action for myofibroblasts [36], it is expressed at lower levels in leiomyomas as compared to myometrium $[26,37,38]$. However, leiomyomas of African Americans expressed a 3.3 fold higher levels of CTGF as compared to Caucasians, and 12.6 and 4.3 fold higher as compared to keloids and incisional scars, respectively. Although the biological significance of these differences needs further investigation, altered expression of many of these genes as compared to their normal tissues counterpart also imply their potential role in various cellular processes that results in tissue fibrosis.

The genes encoding signal transduction and transcription factors represented the largest functional category in leiomyomas and scar tissues. They included several genes such as NR2F1, PNN, Smad4, Smad5, STAT5B, JUN, TGIF2, and ATF1 that were over-expressed while RUNX3, STAT1, STAT6, EGR3, GAS7, Smad1, and EDF1 were underexpressed in leiomyomas as compared to keloid/ incisional scars. We validated the expression of E2F1, RUNX3, EGR3 and TBPIP in leiomyomas [17], keloids, incisional scars and peritoneal adhesions showing a good correlation with microarray data Since activation of these signal transduction pathways and transcription factors regulate the expression of large number of genes with diverse functional activities their altered expression in these tissues could have a considerably more important role in tissue fibrosis than previously considered. Preferential phosphorylation of many of these transcription factors such as Jun, Stats, Smads, Runx and EGRs leads to regulation of target genes involved in cell growth and apoptosis, inflammation, angiogenesis and tissue turnover with central roles in tissue fibrosis [11,17,39-42]

In conclusion, the gene expression profiling involving leiomyomas and their comparison with keloids, incisional scars and peritoneal adhesion indicated that a combination of tissue-specific and common genes differentiate their molecular environments. The tissue-specific differences were not based on the presence/absence of unique genes, but rather the level of expression of selective number of genes accounting for 3 to $12 \%$ of the genes on the array. Although the nature of leiomyomas' development and growth is vastly different from these fibrotic tissues, we speculate that the outcome of their tissue characteristics is influenced by the products of genes regulating cell growth and apoptosis, inflammation, angiogenesis and tissue turnover, and may also be under different tissue-specific regulatory control.

\section{Competing interests}

The author(s) declare that they have no competing interests.

\section{Authors' contributions}

$\mathrm{XL}, \mathrm{QP}$ and NC participated in all aspect of the experimental design and writing of the work presented here. The final microarray gene chips were performed at Interdisciplinary Center for Biotechnology Research at the University of Florida. The analysis of microarray gene expression profiles between the gene chips U95 and 133a was carried out by LL and gene expression analysis and realtime PCR was performed by XL and QP. All the authors read and approved the final manuscript.

\section{Acknowledgements}

We thank Dr. Mick Popp at Interdisciplinary Center for Biotechnology Research at the University of Florida for assistance with microarray chip analysis. The work presented here is supported by a grant HD37432 from the National Institute of Health. The work was presented in part at the 53 rd Annual Meeting of the Society for Gynecological Investigation, Reno NA, and March 2007.

\section{References}

I. Wise LA, Palmer JR, Stewart EA, Rosenberg L: Age-specific incidence rates for self-reported uterine leiomyomata in the Black Women's Health Study. Obstet Gynecol 2005, 105:563-568.

2. Catherino WH, Leppert PC, Stenmark MH, Payson M, Potlog-Nahari C, Nieman LK, Segars JH: Reduced dermatopontin expression is a molecular link between uterine leiomyomas and keloids. Genes Chromosomes Cancer 2004, 40:204-2I7.

3. Al Attar A, Mess S, Thomassen JM, Kauffman CL, Davison SP: Keloid pathogenesis and treatment. Plast Reconstr Surg 2006, I I 7:286-300.

4. Burd A, Huang L: Hypertrophic response and keloid diathesis: two very different forms of scar. Plast Reconstr Surg 2005, I 16:150e-157e.

5. Louw $L:$ The keloid phenomenon: progress toward a solution. Clin Anat 2007, 20:3-14.

6. Slemp AE, Kirschner RE: Keloids and scars: a review of keloids and scars, their pathogenesis, risk factors, and management. Curr Opin Pediatr 2006, 18:396-402.

7. Chegini N: Peritoneal molecular environment, adhesion formation and clinical implication. Front Biosci 2002, 7:e9/-II5.

8. Berto AG, Sampaio LO, Franco CR, Cesar RM Jr., Michelacci YM: A comparative analysis of structure and spatial distribution of decorin in human leiomyoma and normal myometrium. Biochim Biophys Acta 2003, 16 19:98-1 12.

9. Lindblad W]: Perspective article: collagen expression by novel cell populations in the dermal wound environment. Wound Repair Regen 1998, 6: I86-193.

10. Midwood KS, Williams LV, Schwarzbauer JE: Tissue repair and the dynamics of the extracellular matrix. Int J Biochem Cell Biol 2004, 36:1031-1037.

II. Luo X, Ding L, Xu J, Williams RS, Chegini N: Leiomyoma and myometrial gene expression profiles and their responses to gonadotropin-releasing hormone analog therapy. Endocrinology 2005, I 46: 1074-1096.

12. Martin P, Leibovich SJ: Inflammatory cells during wound repair: the good, the bad and the ugly. Trends Cell Biol 2005, 15:599-607.

13. Romagnani P, Lasagni L, Annunziato F, Serio M, Romagnani S: CXC chemokines: the regulatory link between inflammation and angiogenesis. Trends Immunol 2004, 25:20I-209.

14. Szpaderska AM, DiPietro LA: Inflammation in surgical wound healing: friend or foe? Surgery 2005, 137:571-573. 
15. Chen W, Fu X, Sun X, Sun T, Zhao Z, Sheng Z: Analysis of differentially expressed genes in keloids and normal skin with cDNA microarray. J Surg Res 2003, I I 3:208-216.

16. Na GY, Seo SK, Lee S], Kim DW, Kim MK, Kim JC: Upregulation of the NNP-I (novel nuclear protein-I, D2IS2056E) gene in keloid tissue determined by cDNA microarray and in situ hybridization. Br J Dermatol 2004, I 5 I: I | 43- I I 49.

17. Q Pan, $X$ Luo, L Liu, N Chegini: Genomic and proteomic profiling I: Leiomyomas in African Americans and Caucasians. Reprod Biol Endocrinol 2007, 5(I):34.

18. Hinz B, Phan SH, Thannickal VJ, Galli A, Bochaton-Piallat ML, Gabbiani G: The Myofibroblast. One Function, Multiple Origins. Am J Pathol 2007, I70(6): 1807-1816.

19. Stramer BM, Mori R, Martin P: The inflammation-fibrosis link? A Jekyll and Hyde role for blood cells during wound repair. J Invest Dermatol 2007, 127:1009-1017.

20. Wallace WA, Fitch PM, Simpson AJ, Howie SE: Inflammation-associated remodelling and fibrosis in the lung - a process and an end point. Int J Exp Pathol 2007, 88: $103-110$.

21. Wynn TA: Common and unique mechanisms regulate fibrosis in various fibroproliferative diseases. J Clin Invest 2007, I I 7:524-529.

22. Goicoechea S, Arneman D, Disanza A, Garcia-Mata R, Scita G, Otey $C A$ : Palladin binds to Eps8 and enhances the formation of dorsal ruffles and podosomes in vascular smooth muscle cells. J Cell Sci 2006, I I 9:3316-3324.

23. Ronty MJ, Leivonen SK, Hinz B, Rachlin A, Otey CA, Kahari VM, Carpen OM: Isoform-specific regulation of the actin-organizing protein palladin during TGF-betal-induced myofibroblast differentiation. J Invest Dermatol 2006, 1 26:2387-2396.

24. Satish L, Lyons-Weiler J, Hebda PA, Wells A: Gene expression patterns in isolated keloid fibroblasts. Wound Repair Regen 2006, I 4:463-470

25. Nair RR, Solway J, Boyd DD: Expression cloning identifies transgelin (SM22) as a novel repressor of $92-\mathrm{kDa}$ type IV collagenase (MMP-9) expression. J Biol Chem 2006, 28I:26424-26436.

26. Luo X, Ding L, Chegini N: CCNs, fibulin-IC and SI 00A4 expression in leiomyoma and myometrium: inverse association with TGF-beta and regulation by TGF-beta in leiomyoma and myometrial smooth muscle cells. Mol Hum Reprod 2006, I 2:245-256.

27. Chirco R, Liu XW, Jung KK, Kim HR: Novel functions of TIMPs in cell signaling. Cancer Metastasis Rev 2006, 25:99-I I3.

28. Davis GE, Saunders WB: Molecular balance of capillary tube formation versus regression in wound repair: role of matrix metalloproteinases and their inhibitors. J Investig Dermatol Symp Proc 2006, II:44-56.

29. Genis L, Galvez BG, Gonzalo P, Arroyo AG: MTI-MMP: universal or particular player in angiogenesis? Cancer Metastasis Rev 2006, 25:77-86.

30. Mauviel A: Transforming growth factor-beta: a key mediator of fibrosis. Methods Mol Med 2005, I I 7:69-80.

31. Nagase H, Visse R, Murphy G: Structure and function of matrix metalloproteinases and TIMPs. Cardiovasc Res 2006 69:562-573.

32. VanSaun MN, Matrisian LM: Matrix metalloproteinases and celIular motility in development and disease. Birth Defects Res $C$ Embryo Today 2006, 78:69-79.

33. Saarialho-Kere U, Kerkela E, Jahkola T, Suomela S, Keski-Oja J, Lohi J: Epilysin (MMP-28) expression is associated with cell proliferation during epithelial repair. J Invest Dermatol 2002, II9:|4-2|.

34. Ahonen M, Poukkula M, Baker AH, Kashiwagi M, Nagase H, Eriksson JE, Kahari VM: Tissue inhibitor of metalloproteinases-3 induces apoptosis in melanoma cells by stabilization of death receptors. Oncogene 2003, 22:2121-2134.

35. Lambert E, Dasse E, Haye B, Petitfrere E: TIMPs as multifacial proteins. Crit Rev Oncol Hematol 2004, 49:187-198.

36. Leask A, Abraham DJ: TGF-beta signaling and the fibrotic response. FASEB / 2004, 1 8:816-827.

37. Chegini N, Luo X, Ding L, Ripley D: The expression of Smads and transforming growth factor beta receptors in leiomyoma and myometrium and the effect of gonadotropin releasing hormone analogue therapy. Mol Cell Endocrinol 2003, 209:9-16.

38. Sampath D, Zhu Y, Winneker RC, Zhang Z: Aberrant expression of Cyr6I, a member of the CCN (CTGF/Cyr6I/Ceflol
NOVH) family, and dysregulation by 17 beta-estradiol and basic fibroblast growth factor in human uterine leiomyomas. J Clin Endocrinol Metab 200I, 86: I707-17I5.

39. Lee CG, Cho SJ, Kang MJ, Chapoval SP, Lee PJ, Noble PW, Yehualaeshet T, Lu B, Flavell RA, Milbrandt J, Homer RJ, Elias JA: Early growth response gene I-mediated apoptosis is essential for transforming growth factor betal-induced pulmonary fibrosis. J Exp Med 2004, 200:377-389.

40. Miyazono K, Maeda S, Imamura T: Coordinate regulation of cell growth and differentiation by TGF-beta superfamily and Runx proteins. Oncogene 2004, 23:4232-4237.

4I. Thiel G, Cibelli G: Regulation of life and death by the zinc finger transcription factor Egr-I. J Cell Physiol 2002, I 93:287-292.

42. Tien ES, Davis JW, Vanden Heuvel JP: Identification of the CREBbinding protein/p300-interacting protein CITED2 as a peroxisome proliferator-activated receptor alpha coregulator. J Biol Chem 2004, 279:24053-24063.

Publish with Bio Med Central and every scientist can read your work free of charge

"BioMed Central will be the most significant development for disseminating the results of biomedical research in our lifetime. "

Sir Paul Nurse, Cancer Research UK

Your research papers will be:

- available free of charge to the entire biomedical community

- peer reviewed and published immediately upon acceptance

- cited in PubMed and archived on PubMed Central

- yours - you keep the copyright
BioMedcentral 